\title{
PRESENCE AND USE OF AUTOMATED EXTERNAL DEFIBRILLATORS IN OCCUPATIONAL SETTING, BELGIUM
}

\author{
MATHIEU VERBRUGGHE ${ }^{1,2}$, MAURITS DE RIDDER ${ }^{1}$, MOULOUD KALAAI ${ }^{2}$, KATRIEN MORTELMANS ${ }^{2,3}$, \\ PAUL CALLE $^{4,5}$, and LUTGART BRAECKMAN ${ }^{1}$ \\ ${ }^{1}$ Ghent University, Ghent, Belgium \\ Department of Public Health \\ ${ }^{2}$ Mensura, Occupational Health Service, Antwerp, Belgium \\ ${ }^{3}$ Katrien Mortelmans Consulting (KaMoCo), Antwerp, Belgium \\ ${ }^{4}$ Ghent University, Ghent, Belgium \\ Department of Internal Medicine \\ ${ }^{5}$ Maria Middelares General Hospital, Ghent, Belgium \\ Emergency Department
}

\begin{abstract}
Objectives: Few studies focus on out-of-hospital cardiac arrests in the occupational setting. Therefore, this study describes the presence and use of an automated external defibrillator (AED) at Belgian workplaces during the period 2012-2014. Material and Methods: A self-constructed questionnaire was developed and sent to internal prevention counselors. Results: In total, 767 companies filled out the questionnaire. An AED was available in $48.8 \%$ of the companies. Presence mainly depended on the number of persons present in the company (both workers and non-workers (e.g., visitors, clients)) and on some occupational cardiovascular risks but was often not based on a well-conducted risk analysis. Training of workers and AED maintenance were provided appropriately. An AED was used for shocking 23 times of which 10 persons survived. Conclusions: Acquiring an AED in the occupational setting is seldom based on a well-conducted risk analysis. Therefore, instructions and criteria are needed to come to a rational decision. Furthermore, a registry on AED utilization in the workplace (e.g., with data on long-term survival) should be set up. Int J Occup Med Environ Health 2018;31(5):603-611
\end{abstract}

Key words:

Emergency medicine, Cardiopulmonary resuscitation, Automated external defibrillators, AED, Occupational health, Out-of-hospital sudden cardiac arrest

Received: December 9, 2016. Accepted: November 14, 2017.

Corresponding author: Mathieu Verbrugghe, Ghent University, Department of Public Health, De Pintelaan 185 - 4K3, 9000 Ghent, Belgium (e-mail: mathieu.verbrugghe@ugent.be). 


\section{INTRODUCTION}

Out-of-hospital sudden cardiac arrest (SCA) remains a major cause of death, despite improvements in survival the last decades [1,2]. A review from 2010 gives a global average incidence in adults of 55 per 100000 person-years with an average survival of 7\% [1]. Recent figures indicate that $0.3-4.7 \%$ of all out-of-hospital SCAs occur at the workplace [3]. Sudden cardiac arrest first aid provisions include the first steps of the chain of survival:

- early recognition and activation of the local emergency response system,

- initiation of cardiopulmonary reanimation (CPR),

- early shock delivery with an automated external defibrillator (AED) [4].

The chance of survival is negatively associated with the time between the onset of ventricular fibrillation and the resuscitation attempt [5]. The survival rates may decrease by $7 \% / \mathrm{min}$ to $10 \% / \mathrm{min}$ without resuscitation [6]. A maximum 5-min response time is generally considered as the target [7].

The implementation of SCA first aid provisions in the workplace requires a comprehensive approach including adequate training of workers [8], a detailed needs assessment [9], and the verification of SCA first aid provisions' effectiveness [10]. To improve out-of-hospital SCA survival rates, several recommendations on how resuscitation should be practiced comprehensively were formulated, e.g., the European Resuscitation Council Guidelines [11,12]. However, these recommendations are often based on general data concerning public access defibrillators. Unfortunately, appropriate data on the use and utility of AEDs in the workplace, is scarce [13-16]. Only one German study evaluated AED use in an occupational setting [17]. Country-specific studies are needed because SCA risks and survival rates may vary because of differences in worker and workplace characteristics, and the organization of the emergency response system.
The present study aims were to explore:

- Belgian companies' reasons for acquiring (or not) an AED,

- information about AED maintenance, training, knowledge and use,

- results of first aid interventions for SCAs in companies with and without AEDs.

\section{MATERIAL AND METHODS}

A cross-sectional, observational study among companies in Flanders (Belgium) was conducted between February and March 2015. An online questionnaire was sent to all members of Prebes and Flemish associations of prevention counselors (Vereniging Voor Interne Bedrijfsartsen Association des Médecins du Travail Internes - VVIB/ AMTI). After the initial invitation, one reminder was sent.

A composite questionnaire (Appendix 1) was used including general company characteristics; reasons for whether or not acquiring an AED; information about AED placement, inspection and maintenance; CPR/AED training of personnel; and use of CPR/AED in the period 1 January 2012 - 31 December 2014.

The questionnaire was developed by 4 experts and pilottested by 8 prevention counselors. After completing the questionnaire, a group discussion was conducted. Hereafter, comments were processed and the final version was defined.

The study was approved by the Ethical Committee of Ghent University (Belgium).

Descriptive data was presented as frequencies (\%) and medians (interquartile range - IQR). To identify associations between the presence of an AED and relevant characteristics, logistic regression analysis was performed. Variables with a p-value $<0.25$ were entered in a multiple regression model. To perform the statistics, SPSS 23.0 (SPSS Inc., USA) was used. The significance level was set at 0.05 . 


\section{RESULTS}

\section{General characteristics}

The questionnaire was sent to 7115 prevention counselors of which $767(10.8 \%)$ completed the questionnaire. The Table 1 presents the general characteristics. About a half of the companies $(49.3 \%, \mathrm{~N}=378)$ judged themselves as having at least one specific risk for a SCA [12] and had at least one AED available on the site (48.8\%, $\mathrm{N}=374)$. The median external ambulance response time was $10 \mathrm{~min}$ (IQR = 7-12). In $24.9 \%$ ( $\mathrm{N}=191)$ of the companies, the response time was higher than $12 \mathrm{~min}$ (i.e., longer than the goal set for the Belgian emergency care).

\section{Belgian companies' reasons}

\section{of whether or not acquiring an AED}

Main reasons for purchasing an AED were (multiple responses possible): no specific reason/general prevention $(34.5 \%, \mathrm{~N}=209 / 606)$, image $(16.3 \%, \mathrm{~N}=99 / 606)$, by request of the committee for prevention and protection at work $(12.9 \%, \mathrm{~N}=78 / 606)$, high number of external visitors $(12.2 \%, \mathrm{~N}=74 / 606)$, and presence of specific risks $(7.4 \%, \mathrm{~N}=45 / 606)$. In $23.3 \%(\mathrm{~N}=141 / 606)$, the performance of a risk analysis may be assumed (i.e., considering the number of external visitors, the presence of specific risks, and specific other risks). Most of the com-

Table 1. General characteristics of the studied companies ( $\mathrm{N}=767)$ in Belgium, 2012-2014

\begin{tabular}{lcc}
\hline \multicolumn{1}{c}{ Characteristics } & $\mathrm{n}(\%)$ & $\mathrm{Me}(\mathrm{IQR})$ \\
\hline $\begin{array}{l}\text { Type of activity } \\
\text { industrial }\end{array}$ & $400(52.2)$ \\
$\quad$ administrative & $367(47.8)$ \\
Persons present on the site/day [n] & $151(19.7)$ \\
$1-49$ & $151(19.7)$ \\
$50-99$ & $162(21.1)$ \\
$100-199$ & $161(21.0)$ \\
$200-499$ & $142(18.5)$ \\
$\geq 500$ & \\
Presence of SCA risks* & $159(23.2)$ \\
electrocution & $118(17.2)$ \\
heavy physical labor & $67(9.8)$ \\
extreme temperatures & $256(37.3)$ \\
a lot of older employees ( $\geq 45$ years) & $89(12.5)$ \\
others & \\
Presence of procedures for calling and receiving external emergency services & $674(87.9)$ \\
$\quad$ yes & \\
Presence of an AED & $374(48.8)$ \\
yes & \\
External ambulance response time [min] & \\
Maximum time between workstation and AED [min] & \\
\hline
\end{tabular}

SCA - sudden cardiac arrest; AED - automatic external defibrillator; Me - median; IQR - interquartile range.

* Based on Truhlár et al. (2015) [12]. 
Table 2. Logistic regression analysis with the presence of an automated external defibrillator (AED) in the studied companies ( $\mathrm{N}=767$ ) in Belgium, 2012-2014, as dependent variable and potential predictors as independent variables

\begin{tabular}{|c|c|c|c|c|c|c|}
\hline \multirow{2}{*}{ Characteristics } & \multicolumn{3}{|c|}{ Univariate } & \multicolumn{3}{|c|}{ Multivariate } \\
\hline & OR & $95 \% \mathrm{CI}$ & $\mathrm{p}$ & OR & $95 \% \mathrm{CI}$ & $\mathrm{p}$ \\
\hline \multicolumn{7}{|c|}{ Persons present on the site/day ${ }^{\mathrm{a}}[\mathrm{n}]$} \\
\hline $50-99$ & 2.31 & $1.44-3.70$ & 0.000 & 2.27 & $1.41-3.64$ & 0.001 \\
\hline 100-199 & 2.28 & $1.44-3.63$ & 0.000 & 2.27 & $1.42-3.62$ & 0.001 \\
\hline $200-499$ & 2.04 & $1.28-3.25$ & 0.003 & 2.07 & $1.29-3.31$ & 0.002 \\
\hline$\geq 500$ & 4.61 & $2.82-7.55$ & 0.000 & 4.68 & $2.84-7.71$ & 0.000 \\
\hline \multicolumn{7}{|l|}{ Type of activity ${ }^{\mathrm{b}}$} \\
\hline industrial activities & 1.13 & $0.85-1.50$ & 0.389 & & & \\
\hline \multicolumn{7}{|l|}{ Presence of SCA risks ${ }^{c}$} \\
\hline yes & 1.45 & $1.09-1.92$ & 0.011 & 1.33 & $0.99-1.78$ & 0.060 \\
\hline Ambulance response time & 1.02 & $0.99-1.05$ & 0.299 & & & \\
\hline
\end{tabular}

SCA - sudden cardiac arrest.

OR - odds ratio; CI - confidence interval.

${ }^{\text {a }}$ Reference category is $0-49$.

${ }^{\mathrm{b}}$ Reference category is administrative activities.

c Reference category is "no."

panies without an AED had never considered acquiring an AED, $22.5 \%$ ( $\mathrm{N}=162 / 721$ - multiple responses possible) thought it was too expensive, and only $9.3 \%$ $(\mathrm{N}=67 / 721)$ informed the decision on a risk analysis.

Associations between the presence of an AED in the company and relevant characteristics are presented in Table 2. The univariate analysis revealed a significant association with the number of persons present at the company (both workers and non-workers (e.g., visitors, clients)), and the presence of specific risks for SCA. The multivariate analysis showed a significant association with the number of persons present at the company and a borderline significant association with the presence of specific risks for SCA $(p=0.06)$.

\section{Maintenance, (re)training, and information on the presence and use of an AED}

The Table 3 shows the companies' characteristics about AED maintenance, training and information on pres- ence and use of an AED. In 74.2\% ( N = 262) of the companies having an AED, all workers were informed about the presence of the AED. Most of the companies had workers trained to use the AED $(98.6 \%, \mathrm{~N}=348)$ including a CPR training, and organized a refresher course (94.6\%, $\mathrm{N}=334)$ mostly with a time interval of maximum 12 months.

In $81.8 \%(\mathrm{~N}=314 / 384)$ of the companies without an AED, workers followed a CPR training of which $78.9 \%(\mathrm{~N}=302 / 384)$ received a retraining.

\section{First aid interventions for SCAs}

\section{in companies with and without an AED}

Between 1 January 2012 and 31 December 2014, an AED was used for shocking 23 times in 19 (5.1\%) of the companies of which 10 patients survived (43.5\%). Most of the victims were between 40 and 65 years old $(\mathrm{N}=13)$, the youngest being 39 , one victim was older than 65 . Information about age was missing in 8 cases. 
Table 3. Maintenance, (re)training, and information on the presence and use of an automated external defibrillator (AED) in the studied companies $(\mathrm{N}=767)$ in Belgium, 2012-2014

\begin{tabular}{lcc}
\hline \multicolumn{1}{c}{ Variable } & $\mathrm{Me}(\mathrm{IQR})$ \\
\hline AED maintenance contract $(\mathrm{N}=361)$ & $262(72.6)$ \\
yes & $99(27.4)$ \\
no & $285(78.9)$ \\
Internal check-up of the AED $(\mathrm{N}=361)$ & $76(21.1)$ \\
yes & \\
no & $14(4.0)$ \\
Workers in the companies informed & $23(6.5)$ \\
about the presence of an AED $(\mathrm{N}=353)[\%]$ & $54(15.3)$ \\
0 & $262(74.2)$ \\
$<50$ & \\
$\geq 50$ & $348(98.6)$ \\
100 & $5(1.4)$ \\
Workers trained to use an AED $(\mathrm{N}=353)$ & \\
yes & $334(94.6)$ \\
no & $19(5.4)$ \\
Refresher course to use an AED $(\mathrm{N}=353)$ & \\
yes & \\
no & \\
\hline nterval between the internal check-ups of the AED [months] & \\
\hline
\end{tabular}

${ }^{\text {a }}$ Calculated according to the percentage of the valid count. Abbreviations as in Table 1.

In $3.1 \%(\mathrm{~N}=12 / 384)$ of the companies without an $\mathrm{AED}$, one or more CPR attempts took place. In total 15 patients suffered from SCA of whom 6 survived (40\%). Most of the victims were between 40 and 65 years old $(\mathrm{N}=10)$, one victim was 18 years old. Data on the other 4 cases was missing.

\section{DISCUSSION}

Our results show that the decision to acquire an AED is mostly based on the number of workers at the workplace and company specific risks for SCA, and rarely on a wellconducted risk analysis. The absence of clear instructions and precise criteria in the Belgian legislation on first aid at work for making this risk analysis may be an explanation.
An AED was available in $48.8 \%$ out of 767 companies and used for shocking 23 times. These results are lower than the AED provision and utilization in a German study, where $67 \%$ out of 232 companies had at least one AED and used 63 times [17]. However, the German study was conducted solely among occupational physicians mostly working in large-sized enterprises, while we included internal prevention counselors working in a broad range of company sizes. Since publications on AEDs in the workplace are scarce, more studies are needed in order to allow meaningful comparisons.

The American College of Occupational and Environmental Medicine (ACOEM) published a Position Statement 
on AED in the occupational setting to guide the implementation and use of AEDs [5,7]. The guidelines include amongst others:

- coordination with local emergency services,

- training to perform CPR and use an AED,

- placement of the AED to allow initiation of resuscitation within as brief a period of time as possible,

- scheduled equipment maintenance.

In general, companies in our study having an AED, meet the ACOEM recommendations well. A higher percentage of companies with an AED, had workers trained and retrained to provide first aid compared to companies without an AED. It is plausible that acquiring an AED enhances the value added to general first aid. However, well-organized first aid may also result in purchasing an AED. The placement of the AED is not always adequate since the whole work area is not totally covered (out of the 5 min zone). More attention for finding a better location and if necessary acquiring one or more additional AEDs seems to be a good advice for a lot of companies. This study has some limitations. Firstly, the response rate was rather low (convenience sample). Some explanations could be provided. First, the data collection period was rather short (1 February 2015 until 1 March 2015). Second, among the invited prevention counselors, there might be a considerable number of safety engineers which are not responsible for first aid. Furthermore, among the responders, there might be an overrepresentation of companies that are affiliated with the research topic having well-organized first aid systems. Therefore, caution should be taken when generalizing to the larger Belgian context. Secondly, information was missing about a considerable number of SCA cases. Presumably, there was a poor registration about AED or CPR interventions and outcomes in a number of the companies. Therefore, we hesitate to draw conclusions on success rates in the comparison of AED and CPR first aid interventions. Thirdly, it was difficult to define the use of the AED solely for employ- ees because the first aid system and especially the AED component was also used for non-workers present on the grounds of the company (e.g., visitors). The mixed use of the AED in these companies might have influenced data on the use and outcome, even when this data has been closely supervised.

Despite the limitations, important information on the presence and use of AEDs in Belgian companies was provided. Our results may underpin current guidelines on how resuscitation for out-of-hospital SCAs should be practiced comprehensively [11,12] and help inform how training could be improved for example by using selfdirected programs [8]. Furthermore our results may also serve as a base for developing guidelines on the purchase of AEDs in companies and may help these companies to develop a first aid policy for SCAs.

\section{CONCLUSIONS}

This study showed that acquiring an AED in the occupational setting is seldom based on a well-conducted risk analysis. Instructions and criteria for making this risk assessment are needed to come to a rational decision. Most of the companies with an AED have their first aid for SCA well organized with information, training, maintenance and control of the device. Only a minority does not meet the recommendations of ACOEM. However, the choice of placement and the need of additional AEDs require improvement. Besides, the lack of detailed data on SCA cases and items concerning resuscitation, emphasizes the need for a better registration of AED utilizations in the workplace (e.g., with data on long-term survival).

\section{ACKNOWLEDGMENTS}

We would like to thank Prebes and associations of internal prevention counselors in Flanders, Belgium (Vereniging Voor Interne Bedrijfsartsen - Association des Médecins du Travail Internes - VVIB/AMTI) and their members for participating in this study. 


\section{REFERENCES}

1. Berdowski J, Berg RA, Tijssen JG, Koster RW. Global incidences of out-of-hospital cardiac arrest and survival rates: Systematic review of 67 prospective studies. Resuscitation. 2010;81(11):1479-87, https://doi.org/10.1016/j.resuscitation. 2010.08.006.

2. Yamaguchi Y, Woodin JA, Gibo K, Zive DM, Daya MR. Improvements in out-of-hospital cardiac arrest survival from 1998 to 2013. Prehosp Emerg Care. 2017;21(5):616-27, https://doi.org/10.1080/10903127.2017.1308604.

3. Descatha A, Dagrenat C, Cassan P, Jost D, Loeb T, Baer M. Cardiac arrest in the workplace and its outcome: A systematic review and meta-analysis. Resuscitation. 2015;96:30-6, https://doi.org/10.1016/j.resuscitation.2015.07.004.

4. Søreide E, Morrison L, Hillman K, Monsieurs K, Sunde K, Zideman D, et al. The formula for survival in resuscitation. Resuscitation. 2013;84(11):1487-93, https://doi.org/10.1016/ j.resuscitation.2013.07.020.

5. Starr LM. Automated external defibrillation in the occupational setting. J Occup Environ Med. 2012;54(9):1170-6, https://doi.org/10.1097/JOM.0b013e3182677dc8.

6. Larsen MP, Eisenberg MS, Cummings RO, Hallstrom AP. Predicting survival from out-of-hospital cardiac arrest: A graphic model. Ann Emerg Med. 1993;22(11):1652-8, https://doi. org/10.1016/S0196-0644(05)81302-2.

7. Starr LM. ACOEM Position Statement. Automated external defibrillation in the occupational setting. J Occup Environ Med. 2002;44(1):2-7.

8. Mancini ME, Cazzell M, Kardong-Edgren S, Cason CL. Improving workplace safety training using a self-directed CPR-AED learning program. AAOHN J. 2009;57(4):159-67, https://doi.org/10.3928/08910162-20090401-02.

9. Hernandez B, Christensen J. Automatic external defibrillator intervention in the workplace. A comprehensive approach to program development. AAOHN J. 2001;49(2):96-106.
10. Papaleo B, Cangiano G, Calicchia S, Marcellini L, Colagiacomo C, Pera A. [The organization and management of first aid in the workplace: Critical issues and innovations to be introduced]. G Ital Med Lav Ergon. 2012;34(1):71-5. Italian.

11. Perkins GD, Handley AJ, Koster RW, Castrén M, Smyth MA, Olasveengen T, et al. European Resuscitation Council guidelines for resuscitation 2015: Section 2. Adult basic life support and automated external defibrillation. Resuscitation. 2015;95:81-99, https://doi.org/10.1016/j.resuscitation. 2015.07.015.

12. Truhlář A, Deakin C, Soar J, Eldin Abbas Khalifa G, Alfonzo A, Bierens J, et al. European Resuscitation Council guidelines for resuscitation 2015: Section 4. Cardiac arrests in special circumstances. Resuscitation. 2015;95:148-201, https://doi.org/10.1016/j.resuscitation.2015.07.017.

13. Descatha A, Baer M. Automated external defibrillators in the workplace. BMJ. 2008;337:a1816, https://doi.org/ 10.1136/bmj.a1816.

14. Descatha A, Jost D, Carpentier JP. Is the workplace a site of cardiac arrest like any other? Resuscitation. 2009;80:602-3, https://doi.org/10.1016/j.resuscitation.2009.01.018.

15. Descatha A. Automated external defibrillator installation in the workplace: From recommendations to ADE style international registries. J Occup Environ Med. 2012;54(7):765-7, https://doi.org/10.1097/JOM.0b013e3182533528.

16. Descatha A, Schunder-Tatzber S, Hamel TL, Wognin B, Rotthier S, ECOH Working Group, et al. Are there standards of care for cardiac arrest existing in the workplace? Results from a worldwide survey. Resuscitation. 2014;85(9):e145-6, https://doi.org/10.1016/j.resuscitation.2014.05.026.

17. Mayr NP, Mayr T, Tassani P, Martin K. Use of automated external defibrillators in the occupational setting in Germany: A pilot study. J Occup Environ Med. 2012;54(7):789-91, https://doi.org/10.1097/JOM.0b013e318256f65c. 
APPENDIX 1.

\section{QUESTIONNAIRE USED IN STUDY}

ON THE PRESENCE AND USE OF AUTOMATED

EXTERNAL DEFIBRILLATOR (AED) IN FLANDERS,

\section{BELGIUM}

\section{A. General characteristics of the company}

1. How many people (both workers and non-workers e.g., visitors, clients) are present during the day on the site?

$\square$ 0-49

50-99

$100-199$

$200-499$

500 or more

2. What is your company activity type?

$\square$ mainly industrial activities

$\square$ mainly administrative activities

3. Are there specific risks present at the company that could lead to heart problems? (multiple responses possible)

$\square$ no

$\square$ risk of electrocution

$\square$ heavy physical labor

$\square$ extreme temperatures

$\square$ many old workers (> 45 years)

$\square$ other: ...

4. Are there procedures and agreements for calling and receiving external emergency services?

yes

$\square$ no

5. What is the expected response time for the external emergency services? (time between call and arrival)

$\ldots \min$

6. Is there an AED available in the company?

$\square$ yes

$\square$ no

\section{B. Companies having an AED}

7. Since when there is an AED present in your company?
2014

2013

$\square 2012$

$\square 2011$

2010 or earlier

8. How many AEDs are present in your company?

... AEDs

9. What is the mean travel time from a workstation to an AED device (time between call and use AED)?

... $\min$

10. What is the maximum travel time from a workstation to an AED device?

... $\min$

11. Is there an AED maintenance contract with an external company?

$\square$ yes

$\square$ no

12. Is the AED controlled internally?

$\square$ yes

$\square$ no

13. How often is the AED controlled internally?

every ... months

14. Is there someone specifically designated to control the AED?

$\square$ yes

$\square$ no

15. What were the reasons to purchase an AED? (multiple responses possible)

previously need for an AED, but no one present at that time

presence of specific risks

$\square$ by request of the committee for prevention and protection at work

image of the company

$\square$ no specific reason/general prevention

high number of external visitors

$\square$ we take care for the elderly and/or sick

sports activities

other: ... 
16. The AED:

$\square$ is located in a special mounted wall cabinet

$\square$ is not mounted and located at a predefined location

17. The AED is:

$\square$ only available for a limited group of trained workers to use the AEDs

always available for everyone

18. How many workers are trained to use the AED? number of workers: ...

19. After how many months the trained workers receive a refresher course? every ... months

20. Are the other workers informed about the presence of the AED?

no

$\square$ yes, fewer than a half of the workers

$\square$ yes, more than a half of the workers

$\square$ yes, all workers

21. Are the other workers informed about the operating procedure of the AED?

$\square$ no

yes, fewer than a half of the workers

$\square$ yes, more than a half of the workers

yes, all workers

22. How many times the AED has been used to shock in the period between 1 January 2012 and 31 December 2014 (last 3 years)?
$\square 0$
$\square 1$
$\square 2$
$\square 3$
4 or more

23. How many victims survived after a resuscitation where an AED was used?

... victims
24. How many survivors returned to work?

... survivors

25. What was the age of the victims who received a shock with an AED?

... years old

\section{Companies without an AED}

26. How many workers received a training to perform cardiopulmonary resuscitation $(\mathrm{CPR})$ ?

... workers

27. After how many months the trained workers receive a refresher course?

every ... months

28. How many times CPR has been performed in the period between 1 January 2012 and 31 December 2014 (last 3 years)?

$\square 0$

$\square 1$

$\square 2$

$\square 3$

$\square 4$ or more

29. How many victims survived after receiving CPR?

... victims

30. How many survivors returned to work?

... survivors

31. What was the age of the victims who received a CPR?

... years old

32. What were the reasons the company did not acquire an AED? (multiple responses possible) a risk analysis showed that it was not necessary $\square$ the need has not been studied $\square$ we never had an incident where an AED was needed $\square$ nobody has asked for it

$\square$ the cost is too high

$\square$ other: ...

This work is available in Open Access model and licensed under a Creative Commons Attribution-NonCommercial 3.0 Poland License - http://creativecommons.org/ licenses/by-nc/3.0/pl/deed.en. 